\title{
Cushingoid Features in an Obese Female with XY Karyotype
}

\author{
Gunjan Garg, Atul Gogia, Atul Kakar \\ Department of Internal Medicine, Ganga Ram Institute of Post-Graduation Medical Education (GRIPMER), New Delhi, India
}

\begin{abstract}
Disorders of sexual development are congenital in nature. Complete androgen insensitivity syndrome (CAIS) is a rare disorder with an incidence of nearly 1 in 20,000 male births. The majority of patients present with complaints of primary amenorrhoea and are phenotypically female but genotypically male. We report a case of a 40 -year-old female presenting with backache and skin ulcers who was found to have exogenous Cushing's syndrome with long glucocorticoid administration and suspected CAIS. The ulcers were secondary to intramuscular pentazocine injections.

Key words: complete androgen insensitivity syndrome, pentazocine, osteoporosis, Cushing disease
\end{abstract}

\section{CASE}

A 40-year-old obese female presented with complaints of back pain and skin ulcers for one year. There was history of easy bruisability and bony pains. She had not achieved menarche and was taking oral corticosteroids for 20 years. She confessed to self-administering pentazocine injections intramuscularly on her arms and ulnar surface of her hands for severe back pain for the last 2 years. Figures 1 and 2 depict Cushingoid features on general examination. Figure 3 depicts one of the ulcers over the hand. Gynaecological examination revealed a short and blind vagina with scanty and coarse pubic hair with normal breasts (Tanner Stage V). Hormonal investigations are given in Table 1 showing low serum cortisol and low ACTH levels implying exogenous steroid administration. Ultrasound of the pelvis showed absent uterus and gonads. MRI of the spine showed osteoporotic fractures at seventh and eighth thoracic vertebrae with no cord compression. Her karyotypic analysis revealed 46XY genotype.

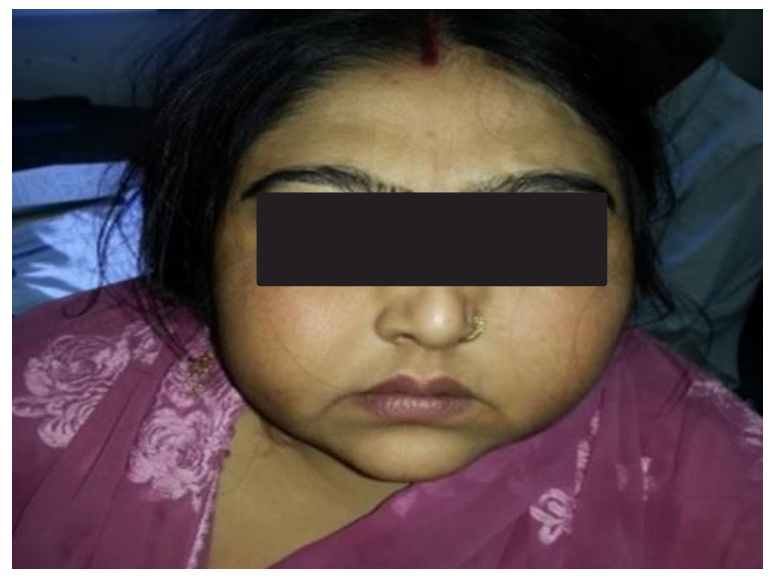

Figure 1. Illustrates moon like facies.

e-ISSN 2308-118X

Printed in the Philippines

Copyright (C) 2014 by the JAFES

Received April 29, 2014. Accepted October 16, 2014.

http://dx.doi.org/10.15605/jafes.029.02.13

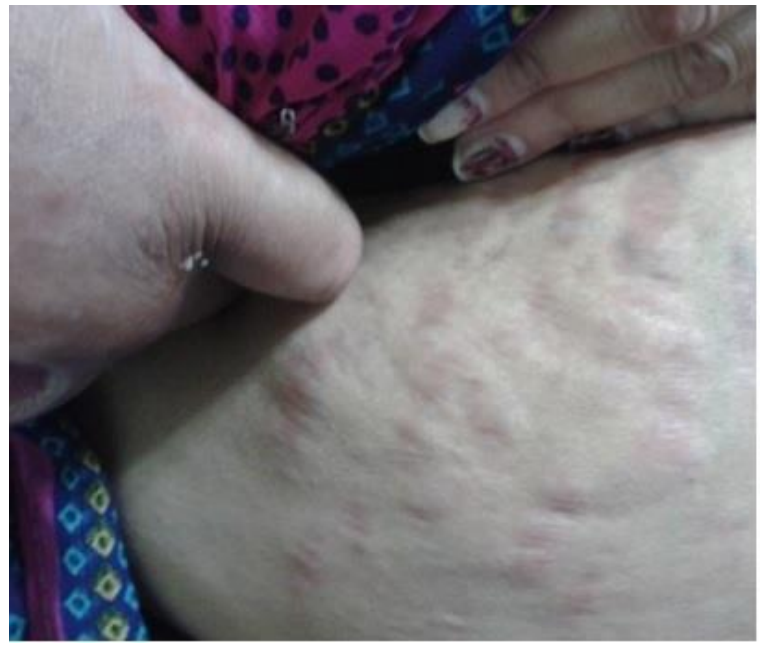

Figure 2. Illustrates purple striae present over abdomen.

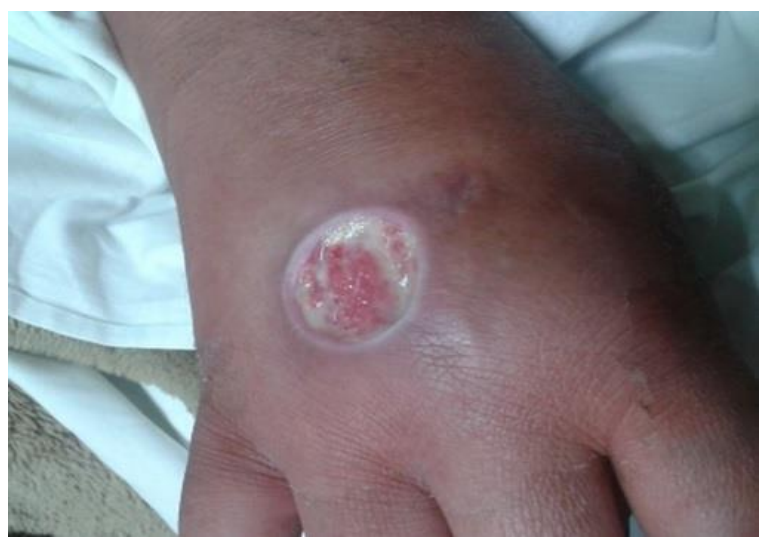

Figure 3. Illustrates punched out ulcers with clear cut margins.

Corresponding author: Prof. Atul Kakar, MD

Ganga Ram Institute of Post-Graduation Medical Education (GRIPMER) Sir Ganga Ram Hospital, Rajinder Nagar

New Delhi 110060, India

Tel. No.: +91 11-25750000

Fax No.: +91 11-25861002

E-mail:atulkakar@hotmail.com 


\begin{tabular}{lll} 
Table 1. Hormonal profile & & \\
\hline \multicolumn{1}{c}{ Parameter } & Result & Normal range \\
\hline Serum cortisol 6 AM & 5 & $6-28 \mathrm{mg} / \mathrm{dl}$ \\
4 PM & 1.3 & $2-12 \mathrm{mg} / \mathrm{dl}$ \\
Serum ACTH & 6 & $9-52 \mathrm{pg} / \mathrm{ml}$ \\
Serum oestradiol & 41.6 & 0 to $30 \mathrm{pg} / \mathrm{mL}$ \\
Serum FSH & 39.3 & $16.7-113.6 \mathrm{IU} / \mathrm{L}$ \\
Serum LH & 16.5 & $1-20 \mathrm{IU} / \mathrm{L}$ \\
Serum testosterone & 0.09 & $0.1-1 \mathrm{ng} / \mathrm{ml}$ \\
Thyroid profile & Normal & \\
\hline
\end{tabular}

A diagnosis of exogenous Cushing's syndrome with pentazocine induced ulcers with complete androgen insensitivity syndrome was made. The patient was given calcium supplements, Vitamin D and zolendronic acid. The ulcers were surgically debrided and spinal casting was done along with analgesics for the spinal fracture. The diagnosis was disclosed to the patient by a psychologist with proper genetic counselling to the family and the patient regarding the genotypic status. She was also counselled for pentazocine deaddiction. The patient is on regular follow up and is doing well.

\section{DISCUSSION}

Our patient had features of weight gain, hirsutism, moon facies and pathognomic Cushing striae. ${ }^{1}$ The patient was suffering from back pain which was due to osteoporotic vertebral collapse. Glucocorticoids are widely prescribed and one of the most misused drug to treat a number of diseases. The long term therapy with oral glucocorticoids and without hormonal treatment in patient with low level of androgen is associated with a significant increase in fracture risk at the hip and spine. According to the 2013 National Osteoporosis Foundation guidelines, people aged $<65$ years who intend to use glucocorticoids for more than 3 months should have their bone density measured before initiating glucocorticoids. If the $\mathrm{T}$ score is above zero, only reassurance is to be given to patient. If the $\mathrm{T}$ score is between 0 to -1.5 then bone densitometry should be repeated after 1-3 years and no medicines are required. Finally if the $\mathrm{T}$ score is -1.5 or less, then the patient has to be given bone protective measures before starting glucocorticoids. Good nutrition, adequate dietary calcium intake, regular exercise should be encouraged. Alcohol and tobacco abstinence should be advised. Various treatment options available are bisphosphonates (alendronate, zolendronic acid, etidronate), calcitonin, calcitriol, hormone replacement therapy in postmenopausal women and recombinant PTH. ${ }^{2}$ The patient was put on a spinal cast, advised not to lift heavy loads and was given analgesics for spinal fractures. For osteoporosis, calcium supplement along with vitamin D and zolendronic acid was given.
Pentazocine is a synthetic opioid used as an analgesic. The ulcers in this patient were deeply punched out, had clear cut and hyperpigmented margins with woody sclerosis of the skin and were microbiologically sterile. These are typical of pentazocine induced ulcers and are present over accessible parts of body like forearms and thigh. ${ }^{3}$ Patients may also develop fibrous myopathy, limb contractures. For pentazocine deaddiction, patient was given gabapentin and clonidine for 7 days and in stabilisation phase gabapentin and naltrexone were given. ${ }^{4}$

The patient had complete androgen insensitivity syndrome based on following facts. Historically, she had primary amenorrhoea. Clinically, patient had sparse and coarse pubic hairs, short and blind vagina, with normal breast development. The patient was karyotypically male with $X Y$ genotype. Affected individuals have male karyotype but female phenotype because of androgen receptor mutation leading to no action of androgen. ${ }^{5}$ Normally, Luteinizing Hormone (LH) induces Leydig cells to produce testosterone but in complete androgen insensitivity syndrome, testosterone levels may increase, decrease or be normal depending upon presence or absence of gonads and production of testosterone from other sources like adrenal glands. All patients with complete androgen insensitivity syndrome should undergo surgery to remove the gonads to avoid cancer. They should also be given hormone replacement therapy for proper development of female exterior characteristics. Recent studies indicate that addition of progesterone to the therapy have little impact on patients without uterus. The patients with partial androgen insensitivity syndrome are given dihydrotestosterone as it does not get aromatized to estrogen in the periphery. Psychological support is the most important aspect for the family as well as for the patient. ${ }^{6}$

References

1. Bista B, Beck N. Cushing syndrome. Indian J Pedatric. 2014;81:158-64 http://dx.doi.org/10.1007/s12098-013-1203-8.

2. Clinician's Guide to prevention and treatment of osteoporosis. http://emir.tums.ac.ir/upfiles/158936855.pdf. Accessed April 25, 2014.

3. Prasad HR, Khaitan BK, Ramam M, Sharma VK, Pandhi RK, Dhawan A, et al. Diagnostic clinical features of pentazocine induced ulcers. Int J Dermatol. 2005;44: 910-15. http://dx.doi.org/10.1111/j.13654632.2004.02291.x.

4. Kumar P, Jain M K. Gabapentin in the Management of Pentazocine Dependence: A Potent Analgesic - Anticraving Agent. JAPI. 2003;51: 673-76.

5. Khollova S, Hrdonkova E, Pomahacova R. Androgen insensitivity syndrome. Ceska Gynekol. 2014;79:38-42.

6. Hughes I A, Davies JD, Bunch TI, Pasterski V, Mastroyannopoulou K, Macdougall J. Androgen insensitivity syndrome. Lancet. 2012;380:1419-28. http://dx.doi.org/10.1016/S0140-6736(12)60071-3.

Articles and any other material published in the JAFES represent the work of the author(s) and should not be construed to reflect the opinions of the Editors or the Publisher. Authors are required to accomplish, sign and submit scanned copies of the JAFES Declaration: that the article represents original material, that is not being considered for publication or has not been published or accepted for publication elsewhere. Consent forms, as appropriate, have been secured for the publication of information about patients; otherwise, authors declared that all means have been exhausted for securing such consent. The authors have signed disclosures that there are no financial or other relationships that might lead to a conflict of interest. All authors are required to submit Authorship Certifications that the manuscript has been read and approved by all authors, and that the requirements for authorship have been met by each author. 